\title{
Article \\ A High-Energy, Narrow-Pulse-Width, Long-Wave Infrared Laser Based on ZGP Crystal
}

\author{
Chuanpeng Qian ${ }^{1,2} \mathbb{D}$, Ting Yu ${ }^{1,2,3, * \mathbb{D}}$, Jing Liu ${ }^{1,2}$, Yuyao Jiang ${ }^{1,2,4}$, Sijie Wang ${ }^{1,2,3}$, Xiangchun Shi ${ }^{1,2,3}$, \\ Xisheng Ye $1,2,3, *(\mathbb{D})$ and Weibiao Chen $1,2,3$
}

1 Laboratory of High Power Fiber Laser Technology, Shanghai Institute of Optics and Fine Mechanics, Chinese Academy of Sciences, Shanghai 201800, China; cpqian@siom.ac.cn (C.Q.); liujing@siom.ac.cn (J.L.); jiangyuyao@shu.edu.cn (Y.J.); wangsijie@siom.ac.cn (S.W.); shixc@siom.ac.cn (X.S.); wbchen@siom.ac.cn (W.C.)

2 Shanghai Key Laboratory of All Solid-State Laser and Applied Techniques, Shanghai Institute of Optics and Fine Mechanics, Chinese Academy of Sciences, Shanghai 201800, China

3 College of Materials Science and Opto-Electronic Technology, University of Chinese Academy of Sciences, Beijing 100049, China

4 College of Science, Shanghai University, Shanghai 200444, China

* Correspondence: yuting@siom.ac.cn (T.Y.); xsye@siom.ac.cn (X.Y.)

check for

updates

Citation: Qian, C.; Yu, T.; Liu, J.; Jiang, Y.; Wang, S.; Shi, X.; Ye, X.; Chen, W. A High-Energy,

Narrow-Pulse-Width, Long-Wave Infrared Laser Based on ZGP Crystal. Crystals 2021, 11, 656. https:// doi.org/10.3390/cryst11060656

Academic Editors: Xiaoming Duan, Renqin Dou, Linjun Li and Xiaotao Yang

Received: 17 May 2021

Accepted: 8 June 2021

Published: 9 June 2021

Publisher's Note: MDPI stays neutral with regard to jurisdictional claims in published maps and institutional affiliations.

Copyright: (c) 2021 by the authors. Licensee MDPI, Basel, Switzerland. This article is an open access article distributed under the terms and conditions of the Creative Commons Attribution (CC BY) license (https:// creativecommons.org/licenses/by/ $4.0 /)$.

\begin{abstract}
In this paper, we present a high-energy, narrow pulse-width, long-wave infrared laser based on a $\mathrm{ZnGeP}_{2}$ (ZGP) optical parametric oscillator (OPO). The pump source is a $2.1 \mu \mathrm{m}$ three -stage Ho:YAG master oscillator power-amplifier (MOPA). At a repetition frequency of $1 \mathrm{kHz}$, the Ho:YAG MOPA system outputs the maximal average power of $52.1 \mathrm{~W}$, which corresponds to the shortest pulse width of $14.40 \mathrm{~ns}$. By using the Ho:YAG MOPA system as the pump source, the maximal average output powers of $3.15 \mathrm{~W}$ at $8.2 \mu \mathrm{m}$ and $11.4 \mathrm{~W}$ at $2.8 \mu \mathrm{m}$ were achieved in a ZGP OPO. The peak wavelength and linewidth (FWHM) of the long-wave infrared laser were $8156 \mathrm{~nm}$ and $270 \mathrm{~nm}$, respectively. At the maximal output level, the pulse width and beam quality factor $M^{2}$ were measured to be $8.10 \mathrm{~ns}$ and 6.2 , respectively.
\end{abstract}

Keywords: long-wave infrared; $\mathrm{ZnGeP}_{2}$ crystal; Ho:YAG MOPA

\section{Introduction}

As an important atmospheric transmission window, long-wave infrared lasers $(8-12 \mu \mathrm{m})$ have been extensively applied in many fields, such as lidar, spectroscopy, and national defense [1,2]. Among the many ways to obtain a long-wave infrared laser, the optical parametric oscillator is an attractive approach due to its wide wavelength-tuning range and high conversion efficiency [3]. As the core component, the characteristics of nonlinear optical crystals determine the performance of nonlinear frequency conversion. At present, nonlinear crystals suitable for generating a long-wave infrared laser mainly include OP-GaAs, AgGaSe $2, \mathrm{CdSe}$, $\mathrm{BaGa}_{4} \mathrm{Se}_{7}$, and $\mathrm{ZnGeP} 2$ (ZGP).

The nonlinear coefficient of OP-GaAs is very large $\left(\mathrm{d}_{14}=94 \mathrm{pm} / \mathrm{V}\right)$, and it was used to achieve an average pulse energy of $0.18 \mathrm{~mJ}$ at $8.5 \mu \mathrm{m}$ [4] and $16.2 \mu \mathrm{J}$ at $10.6 \mu \mathrm{m}$ [5], corresponding to the repetition frequencies of 2 and $50 \mathrm{kHz}$, respectively. AgGaSe 2 has a low damage threshold $\left(18 \mathrm{MW} / \mathrm{cm}^{2}\right)$, which limits its ability to obtain a large-energy long-wave infrared laser. The highest energy of a long-wave infrared laser by AgGaSe 2 was about hundreds of microjoules [6-8]. CdSe has a small nonlinear coefficient $\left(\mathrm{d}_{31}=18 \mathrm{pm} / \mathrm{V}\right)$ and a moderate damage threshold $\left(56 \mathrm{MW} / \mathrm{cm}^{2}\right)$. Due to its weak walk-off effect, the disadvantage of a small nonlinear coefficient can be compensated by increasing the crystal length. The pulse energy of a long-wave infrared laser achieved $1.05 \mathrm{~mJ}$ at $10.1 \mu \mathrm{m}$ [9] and $0.8 \mathrm{~mJ}$ at $11 \mu \mathrm{m} \mathrm{[10].} \mathrm{BaGa}_{4} \mathrm{Se}_{7}$ has a very large damage threshold $\left(557 \mathrm{MW} / \mathrm{cm}^{2}\right)$ and an acceptable nonlinear coefficient $\left(\mathrm{d}_{11}=24.3 \mathrm{pm} / \mathrm{V}\right)$, but its low thermal conductivity makes it unsuitable for obtaining a high-power long-wave infrared laser. In 2018, Zhao et al. 
obtained an average pulse energy of $0.31 \mathrm{~mJ}$ at $8.92 \mu \mathrm{m}$ [11] with a repetition frequency of $1 \mathrm{kHz}$. The nonlinear coefficient of a ZGP crystal is high $\left(\mathrm{d}_{14}=75 \mathrm{pm} / \mathrm{V}\right)$, and its thermal conductivity and damage threshold perform well among these nonlinear crystals. Using a ZGP crystal, the largest pulse energy of $45 \mathrm{~mJ}$ at $8.0 \mu \mathrm{m}$ was achieved [12]. This result was achieved under a low repetition frequency $(1 \mathrm{~Hz})$. At a kilohertz frequency, the ZGP crystal obtained pulse energy of $1.26 \mathrm{~mJ}$ at $8.2 \mu \mathrm{m}$ [13] and $0.35 \mathrm{~mJ}$ at $9.8 \mu \mathrm{m}$ [14], with a repetition frequency of $10 \mathrm{kHz}$.

We demonstrate a high-energy, narrow-pulse-width, long-wave infrared laser with repetition frequency of $1 \mathrm{kHz}$ based on a ZGP crystal. The pump source is a $2.1 \mu \mathrm{m}$ Ho:YAG MOPA laser that can output a highest average energy of $52.1 \mathrm{~mJ}$ at $1 \mathrm{kHz}$. The pulse width and beam factor $M^{2}$ were measured to be $14.40 \mathrm{~ns}$ and 1.3 , respectively. Then, a ZGP OPO with a four-mirror ring-cavity structure was used. The output energy of the long-wave infrared ZGP OPO was $3.15 \mathrm{~mJ}$ for the idler and $11.4 \mathrm{~mJ}$ for the signal. The pulse width and beam factor $M^{2}$ were measured to be $8.10 \mathrm{~ns}$ and 6.2 at the maximal output level.

\section{Experimental Setup}

The experimental setup of the Ho:YAG MOPA system is shown in Figure 1, which contains a Q-switched Ho:YAG oscillator and a three-stage Ho:YAG MOPA system. The acousto-optical modulator (AOM) Q-switched Ho:YAG oscillator had a compact L-shaped structure that consisted of an input mirror (M1) with antireflection (AR) for $1.9 \mu \mathrm{m}$ and high-reflection (HR) for $2.1 \mu \mathrm{m}$, an output coupler (M2) with transmittance of $60 \%$ at $2.1 \mu \mathrm{m}$, and a thin-film polarizer (M3) with AR for s-polarized $2.1 \mu \mathrm{m}$ and HT for p-polarized $2.1 \mu \mathrm{m}$. Its physical-cavity length was $150 \mathrm{~mm}$. The Ho:YAG crystal in the oscillator with dopant concentration of $0.5 \%$, diameter of $5 \mathrm{~mm}$, and length of $30 \mathrm{~mm}$ was single-ended pumped by a Tm:YLF laser with the $1 / e^{2}$ beam-waist diameter of $0.34 \mathrm{~mm}$ and maximal power of $28 \mathrm{~W}$.

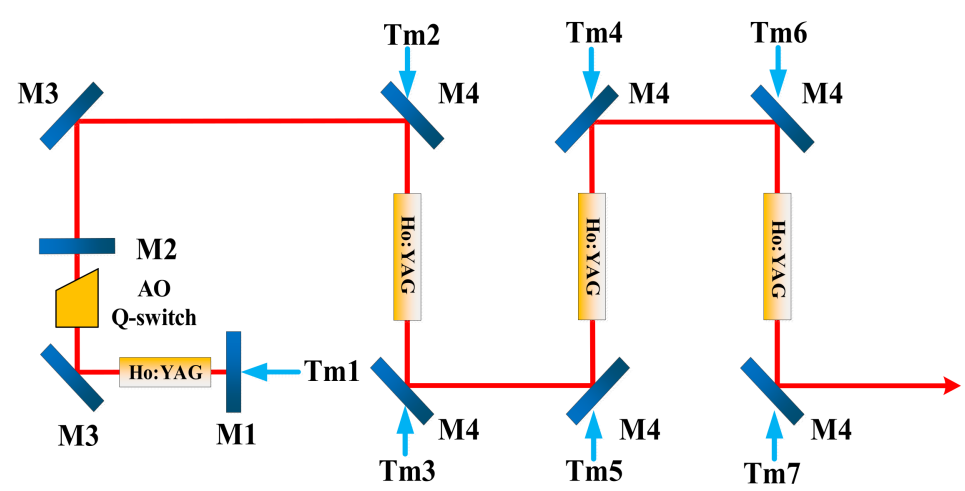

Figure 1. Experimental setup of three-stage Ho:YAG MOPA system.

The three-stage Ho:YAG MOPA system was designed and operated at a PRF of $1 \mathrm{kHz}$. The three Ho:YAG crystals with a dopant concentration of $0.3 \%$, diameter of $5 \mathrm{~mm}$, and length of $70 \mathrm{~mm}$ were dual-ended pumped by six Tm:YLF lasers. The output powers of the six Tm:YLF lasers were about $40 \mathrm{~W}$. The beam diameters of the pump in the three Ho:YAG crystals were $0.83,1.4$, and $1.9 \mathrm{~mm}$, respectively.

The experimental setup of ZGP OPO is shown in Figure 2. The ZGP OPO had a fourmirror ring cavity structure, including two mirrors (M5) with an AR p-polarized pump laser and HR idler laser, a mirror (M6) with an AR pump and signal laser and an HR idler laser, and an output coupler (M7) with transmittance of $45 \%$ for the idler laser. In order to more accurately measure the power of the idler and the signal laser two M8 mirrors and one M7 mirror were used. The oscillator resonated with the single idler laser, and the ambient humidity of the experiment facility was kept at about $10 \%$. Both measures were designed to avoid damaging the coating of the ZGP crystal caused by water absorption around the wavelength of the signal laser. The physical length of the ring cavity was about 
$118 \mathrm{~mm}$. With the ZGP crystal, the wavelength of the OPO was continuously tunable from 3.8 to $12.4 \mu \mathrm{m}$ [15]. However, the optical-to-optical efficiency of the OPO decreased with the increase in wavelength. In this experiment, we adjusted the wavelength of the idler laser to $8.2 \mu \mathrm{m}$. The ZGP crystal had an aperture of $6 \mathrm{~mm} \times 6 \mathrm{~mm}$ and a length of $30 \mathrm{~mm}$, cut at an angle of $\theta=50.8^{\circ}$ with respect to Type I phase matching. Both ends of the ZGP crystal (School of Chemical Engineering and Technology, HIT, Ha'erbin, China) were coated with HT for the pump, signal, and idler laser. The absorption coefficients of the ZGP crystal at the $2.1 \mu \mathrm{m}$ pump laser and $8.2 \mu \mathrm{m}$ idler laser were measured to be 0.03 and $0.01 \mathrm{~cm}^{-1}$, respectively. The pump laser from the Ho:YAG MOPA system was focused onto the ZGP crystal with a $1 / e^{2}$ beam diameter of $3.6 \mathrm{~mm}$. The crystals of the entire experimental apparatus, including Tm:YLF, Ho:YAG, and ZGP, were all wrapped in indium foil and installed into copper blocks that were cooled by the chiller. The temperatures of the Tm:YLF, Ho:YAG, and ZGP crystals were controlled to be 16,18 , and $20^{\circ} \mathrm{C}$, respectively.

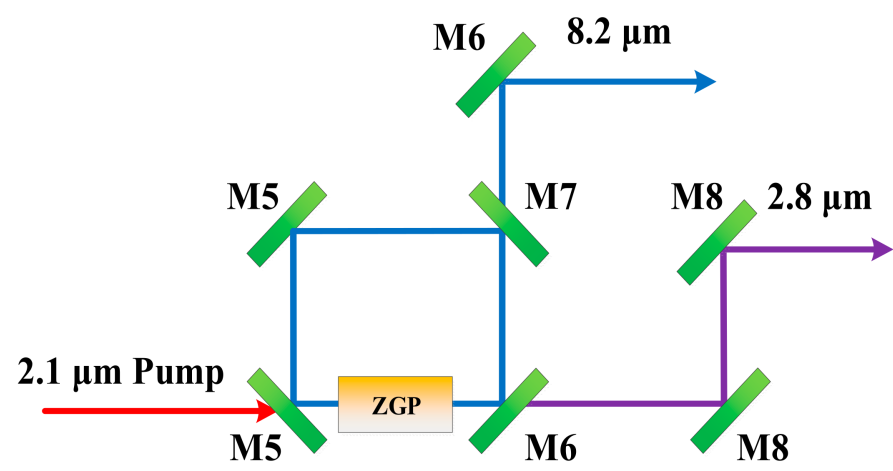

Figure 2. Experimental setup of ZGP OPO.

\section{Results and Discussion}

In this experiment, the output powers were measured by the same power meter (Ophir PM 150). The output performances of the Ho:YAG oscillator are shown in Figure 3. The threshold pump power of the Ho:YAG oscillator was about $8 \mathrm{~W}$. Pump power of $28.0 \mathrm{~W}$ and a maximal average output power of $5.42 \mathrm{~W}$ were achieved, corresponding to the opticalto-optical conversion efficiency of $19.4 \%$. The optical-to-optical conversion efficiency was low because we used a small mold volume to achieve the $2.1 \mu \mathrm{m}$ narrow-pulse-width laser output. Using an InGaAs detector and a $1 \mathrm{GHz}$ digital oscilloscope (Tektronix DPO4102B), we measured the minimal full-width half maximum (FWHM) of the pulse profile to be $11.56 \mathrm{~ns}$, which is shown in Figure 3a. Figure 3b shows the beam-quality factor $M^{2}$ of the oscillator that was measured by the $90 / 10$ knife-edge method. Under the maximal output condition of the Ho:YAG oscillator, the beam quality factor $M^{2}$ in the $\mathrm{x}$ and $\mathrm{y}$ directions was 1.19 and 1.26 , respectively.
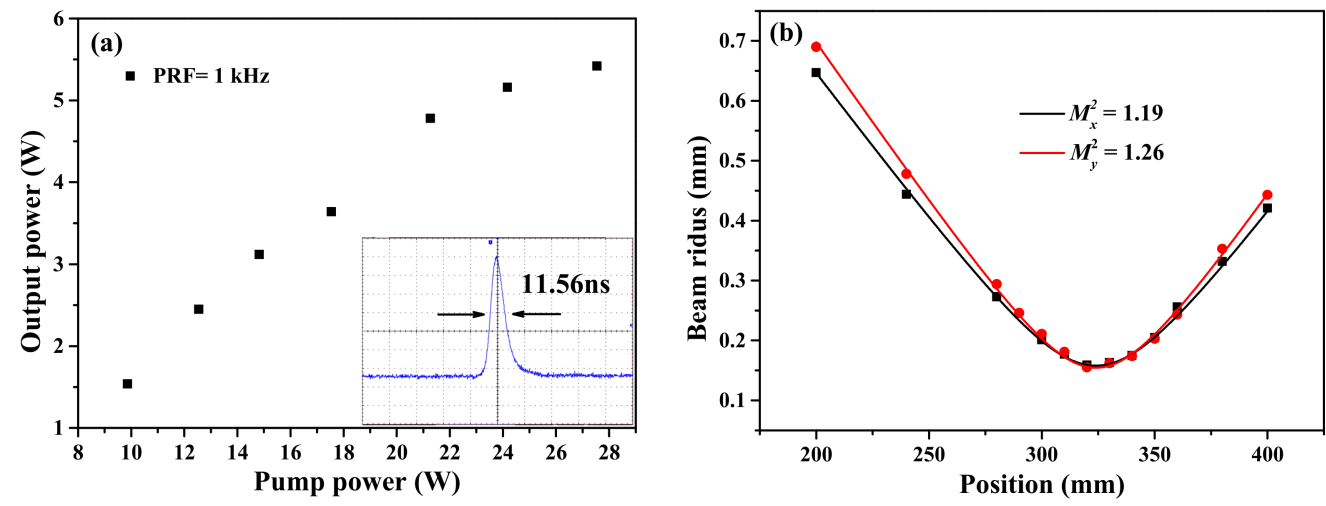

Figure 3. (a) Output power and pulse width, and (b) beam quality factor of Ho:YAG oscillator. 
The $2.1 \mu \mathrm{m}$ laser produced by the oscillator was injected into the Ho:YAG crystal in the primary amplifier after being transformed by a set of coupling lenses, as shown in Figure 4a. The output powers for each amplifier stage were 18.14, 37.5, and $52.4 \mathrm{~W}$, corresponding to slope efficiencies of $24.7 \%, 36.0 \%$, and $33.4 \%$, respectively. When the amplifier moved from the first stage to the third, the pulse width of the $2.1 \mu \mathrm{m}$ laser slightly increased, which was measured to be $12.72,13.38$, and 14.40 ns. Compared to the Ho:YAG oscillator, the beam quality factor $M^{2}$ of the Ho:YAG amplifier very slightly deteriorated, with 1.20 and 1.28 for the $x$ and $y$ directions, respectively. The final pulse width and beam quality of the Ho:YAG MOPA system are shown in Figure $4 b, c$ respectively.
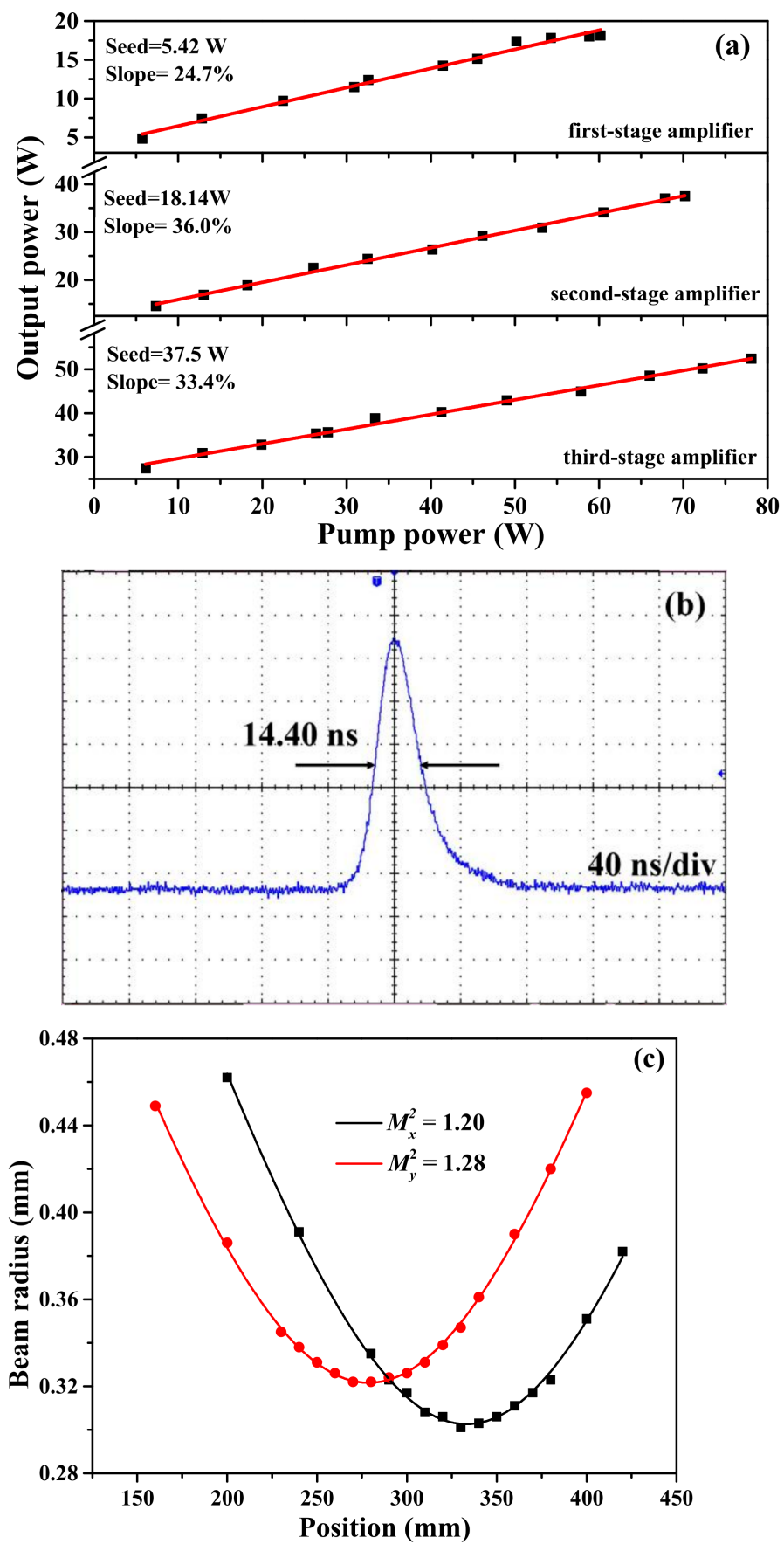

Figure 4. (a) Output powers, (b) pulse width, and (c) beam quality factor $M^{2}$ of three-stage Ho:YAG amplifier. 
As shown in Figure 5a, the average output power of ZGP OPO was measured with an incident pump power of $52.4 \mathrm{~W}$. The pump laser was injected into the crystal in a divergent way to avoid damaging the end face with the thermal-lens effect. The divergence angle was about $6 \mathrm{mrad}$. During the experiment, we gradually reduced the size of the pump spot to obtain the highest pulse energy of the long-wave infrared laser. Lastly, the beam diameter at the front-end face of the ZGP crystal was $\sim 3.6 \mathrm{~mm}$. Threshold pump power was about $21.8 \mathrm{~W}$ and the maximal average output power of the ZGP OPO was about $3.15 \mathrm{~W}$ at $8.2 \mu \mathrm{m}$ and $11.4 \mathrm{~W}$ at $2.8 \mu \mathrm{m}$, corresponding to the slope efficiency of about $10.1 \%$ and $37.0 \%$. The beam quality factor $M^{2}$ was measured and calculated to be 6.2 at the maximal output power, which is shown in Figure $5 b$.
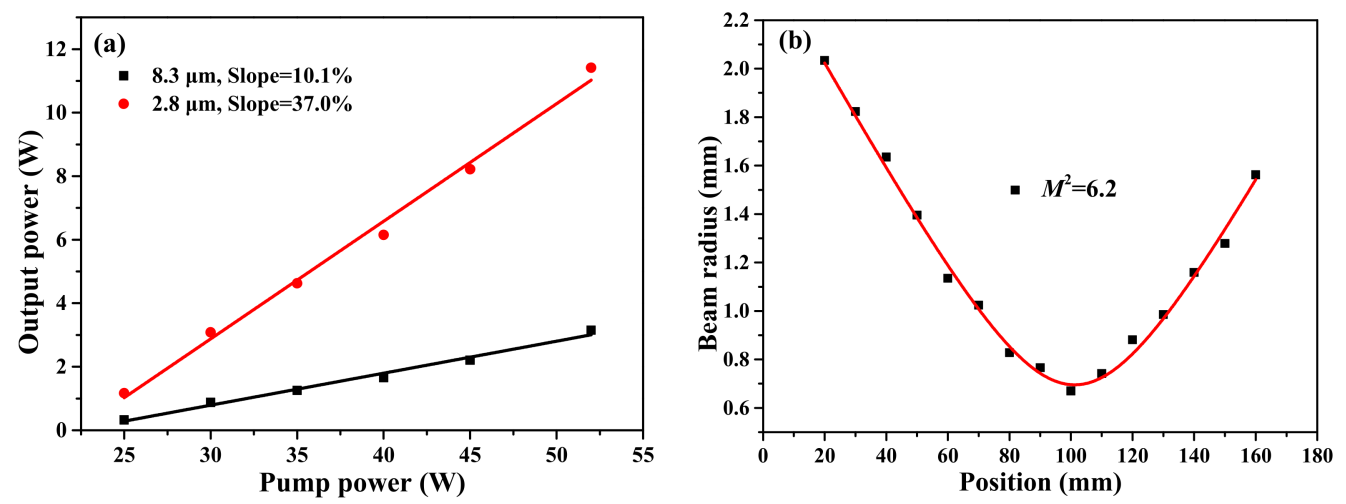

Figure 5. (a) Output power, and (b) beam quality factor $M^{2}$ of ZGP OPO.

In the experimental process, the damage threshold of the ZGP crystal had great correlation with the repetition frequency of the pump laser. In our previous work, which used a $3 \mathrm{kHz}$ Ho:YAG MOPA system to pump ZGP OPO [16], the ZGP crystal was damaged when the pump power was $\sim 73 \mathrm{~W}$ and the spot radius was $1.28 \mathrm{~mm}$, corresponding to peak power density of $54.9 \mathrm{MW} / \mathrm{cm}^{2}$. We also measured the damage threshold of the ZGP crystal at $10 \mathrm{kHz}$ repetition frequency, and it was about $25.7 \mathrm{MW} / \mathrm{cm}^{2}$. However, under the condition of $1 \mathrm{kHz}$ repetition frequency, the ZGP crystal remained undamaged when the peak power density of the pump reached $60 \mathrm{MW} / \mathrm{cm}^{2}$. For the same ZGP crystal, the damage threshold increased by more than two times under the same heat-dissipation conditions as the repetition frequency of the pump laser decreased from 10 to $1 \mathrm{kHz}$. This phenomenon could have been related to the time during which the laser was acting on the coating film. At a high repetition rate, a longer treatment time led to a higher film temperature, and this made the coating film of the ZGP crystal more vulnerable to damage.

Because the InGaAs detector could not respond to a long-wave infrared laser, we employed an $\mathrm{HgCdTe}$ detector combined with a signal amplifier to measure the pulse width of the $8.2 \mu \mathrm{m}$ idler laser, which is shown in Figure 6a. The FWHM pulse width was 8.10 ns with the peak power of 0.39 MW. Using a monochromator spectrograph (Zolix, omni- $\lambda$ 300i), the idler spectrum was measured and is shown in Figure 6b. Peak wavelength was $8156 \mathrm{~nm}$. The corresponding linewidth (FWHM) was approximately $270 \mathrm{~nm}$. 

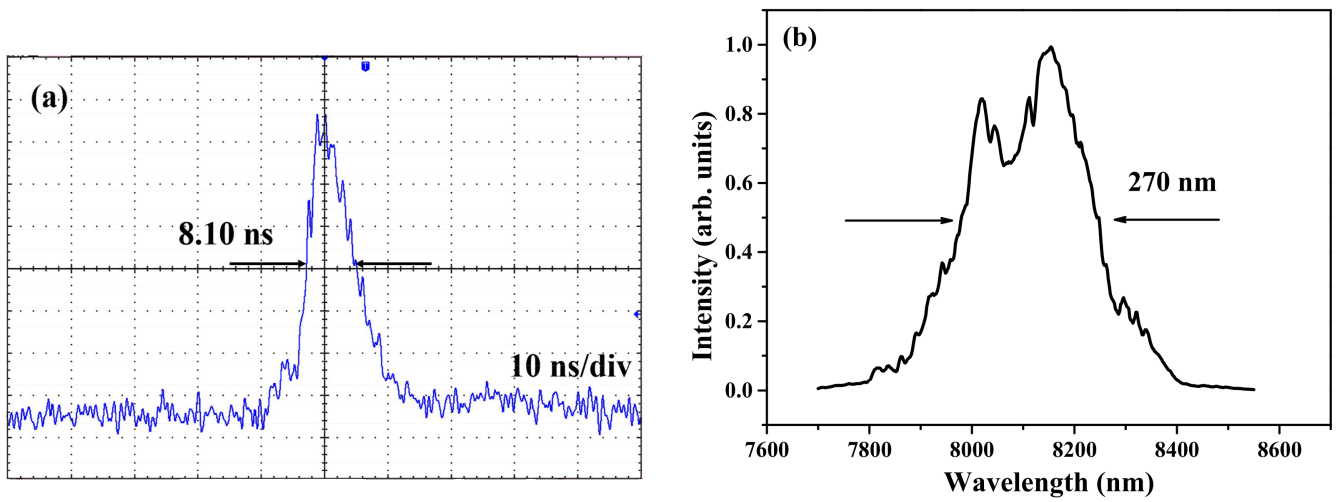

Figure 6. (a) Pulse width, (b) ZGP OPO spectrum.

\section{Conclusions}

The Ho:YAG oscillator was Q-switched at $1 \mathrm{kHz}$, and the pulse width was $12 \mathrm{~ns}$. The successive three-stage Ho:YAG amplifier stages increased the maximal average output power up to $52.1 \mathrm{~W}$ with a pulse width of $\sim 14 \mathrm{~ns}$, corresponding to the beam quality factors $M^{2}$ of 1.20 and 1.28 for the horizontal and vertical directions, respectively. With the above Ho:YAG MOPA system, maximal output powers of $3.15 \mathrm{~W}$ at $8.2 \mu \mathrm{m}$ and $11.4 \mathrm{~W}$ at $2.8 \mu \mathrm{m}$ were produced in ZGP OPO, with an idler laser output energy of $3.15 \mathrm{~mJ}$ and a pulse width of $8.10 \mathrm{~ns}$. The linewidth of the long-wave infrared laser was $270 \mathrm{~nm}$ at a central wavelength of $8156 \mathrm{~nm}$. Its beam quality factors $M^{2}$ were 6.2. As far as we know, this is the largest reported amount of pulse energy in a long-wave infrared laser at a kilohertz repetition-frequency band.

Author Contributions: Experiment and writing original draft preparation: C.Q., Y.J. and S.W.; formal analysis: T.Y., J.L. and X.S.; review and editing: X.Y. and W.C. All authors have read and agreed to the published version of the manuscript.

Funding: This work was supported by the National Natural Science Foundation of China (NSFC) (62005300).

Institutional Review Board Statement: Not applicable.

Informed Consent Statement: Not applicable.

Data Availability Statement: Not applicable.

Conflicts of Interest: The authors declare no conflict of interest.

\section{References}

1. Webber, M.E.; Pushkarsky, M.; Patel, C.K.N. Optical detection of chemical warfare agents and toxic industrial chemicals: Simulation. J. Appl. Phys. 2005, 97, 113101. [CrossRef]

2. Petrov, V. Frequency down-conversion of solid-state laser sources to the mid-infrared spectral range using non-oxide nonlinear crystals. Prog. Quantum Electron. 2015, 42, 1-106. [CrossRef]

3. Hildenbrand, A.; Kieleck, C.; Tyazhev, A.; Marchev, G.; Stöppler, G.; Eichhorn, M.; Schunemann, P.G.; Panyutin, V.L.; Petrov, V. Laser damage of the nonlinear crystals $\mathrm{CdSiP}_{2}$ and $\mathrm{ZnGeP}_{2}$ studied with nanosecond pulses at 1064 and $2090 \mathrm{~nm}$. Opt. Eng. 2014, 53, 122511. [CrossRef]

4. Gutty, F.; Grisard, A.; Larat, C.; Papillon, D.; Schwarz, M.; Gerard, B.; Ostendorf, R.; Rattunde, M.; Wagner, J.; Lallier, E. 140 W peak power laser system tunable in the LWIR. Opt. Express 2017, 25, 18897-18906. [CrossRef] [PubMed]

5. Wueppen, J.; Nyga, S.; Jungbluth, B.; Hoffmann, D. $1.95 \mu \mathrm{m}$-pumped OP-GaAs optical parametric oscillator with $10.6 \mu \mathrm{m}$ idler wavelength. Opt. Lett. 2016, 41, 4225-4228. [CrossRef] [PubMed]

6. Boyko, A.A.; Kostyukova, N.Y.; Marchev, G.M.; Pasiskevicius, V.; Kolker, D.B.; Zukauskas, A.; Petrov, V. Rb:PPKTP optical parametric oscillator with intracavity difference-frequency generation in AgGaSe 2 . Opt. Lett. 2016, 41, 2791-2794. [CrossRef] [PubMed]

7. Boyko, A.A.; Marchev, G.M.; Petrov, V.; Pasiskevicius, V.; Kolker, D.B.; Zukauskas, A.; Kostyukova, N.Y. Intracavity-pumped, cascaded AgGaSe 2 optical parametric oscillator tunable from 5.8 to $18 \mu \mathrm{m}$. Opt. Express 2015, 23, 33460-33465. [CrossRef] [PubMed] 
8. Gerhards, M. High energy and narrow bandwidth mid IR nanosecond laser system. Opt. Commun. 2004, 241, 493-497. [CrossRef]

9. Chen, Y.; Liu, G.Y.; Yang, C.; Yao, B.Q.; Wang, R.X.; Mi, S.Y.; Yang, K.; Dai, T.Y.; Duan, X.M.; Ju, Y.L. 1 W, 10.1 ㅆm, CdSe optical parametric oscillator with continuous-wave seed injection. Opt. Lett. 2020, 45, 2119-2122. [CrossRef] [PubMed]

10. Chen, Y.; Yang, C.; Liu, G.Y.; Yao, B.Q.; Wang, R.X.; Yang, K.; Mi, S.Y.; Dai, T.Y.; Duan, X.M.; You, Y.L. $11 \mu$ m, high beam quality idler-resonant CdSe optical parametric oscillator with continuous-wave injection-seeded at $2.58 \mu \mathrm{m}$. Opt. Express 2020, 28, 17056-17063. [CrossRef] [PubMed]

11. Zhao, B.R.; Chen, Y.; Yao, B.Q.; Yao, J.Y.; Guo, Y.W.; Wang, R.X.; Dai, T.Y.; Duan, X.M. High-efficiency, tunable 8-9 $\mu$ m BaGa ${ }_{4} \mathrm{Se}_{7}$ optical parametric oscillator pumped at $2.1 \mu \mathrm{m}$. Opt. Mater. Express 2018, 8, 3332-3337. [CrossRef]

12. Bakkland, A.; Fonnum, H.; Lippert, E.; Haakestad, M.W. Long-wave infrared source with $45 \mathrm{~mJ}$ pulse energy based on nonlinear conversion in $\mathrm{ZnGeP}_{2}$. Conf. Lasers Electro Opt. 2016. [CrossRef]

13. Liu, G.Y.; Chen, Y.; Yao, B.Q.; Yang, K.; Qian, C.P.; Dai, T.Y.; Duan, X.M. Study on long-wave infrared ZnGeP 2 subsequent optical parametric amplifiers with different types of phase matching of $\mathrm{ZnGeP}_{2}$ crystals. Appl. Phys. B 2019, 125, 233. [CrossRef]

14. Liu, G.Y.; Chen, Y.; Yao, B.Q.; Wang, R.X.; Yang, K.; Yang, C.; Mi, S.Y.; Dai, T.Y.; Duan, X.M. 3.5 W long-wave infrared ZnGeP 2 optical parametric oscillator at $9.8 \mu \mathrm{m}$. Opt. Lett. 2020, 45, 2347-2350. [CrossRef] [PubMed]

15. Vodopyanov, K.L.; Ganikhanov, F.; Maffetone, J.P.; Zwieback, I.; Ruderman, W. ZnGeP 2 optical parametric oscillator with 3.8-12.4 $\mu \mathrm{m}$ tunability. Opt. Lett. 2000, 25, 841-843. [CrossRef] [PubMed]

16. Qian, C.P.; Yu, T.; Liu, J.; Jiang, Y.Y.; Wang, S.J.; Shi, X.C.; Ye, X.S.; Chen, W.B. 5.4 W, 9.4 ns pulse width, long-wave infrared ZGP OPO pumped by Ho:YAG MOPA system. IEEE Photonics J. 2021, 17. in press. 